PRE PROOF VEERSION OF: Hanley Santos, G. and Coomber, R. (2016) 'The risk environment of anabolic-androgenic steroid users in the UK: Examining motivations, practices and accounts of use', International Journal of Drug Policy

\title{
The risk environment of anabolic-androgenic steroid users in the UK: Examining motivations, practices and accounts of use
}

Gisella Hanley Santos ${ }^{\mathrm{a}}$ and Ross Coomber ${ }^{\mathrm{b}}$

a School of Law, Criminology and Government, Plymouth University, Drake Circus, Plymouth PL4 8AA, UK

gisella.hanleysantos@plymouth.ac.uk (corresponding author)

${ }^{\mathrm{b}}$ Griffith Criminology Institute, Griffith University, Mt Gravatt Campus, Queensland 4122, Australia r.coomber@griffith.edu.au

\section{Abstract}

Background: The numbers using illicit anabolic-androgenic steroids are a cause of concern for those seeking to reduce health harms. Using the 'risk environment' as a conceptual framework to better comprehend how steroid users’ practices and perspectives impact on health risks, this paper examines steroid user motivations, patterns of use, and the ways in which these practices are accounted for. 
Methods: As part of a wider mixed-method study into performance and image enhancing drug (PIED) use and supply in one mid-sized city in South West England, qualitative interviews were undertaken with 22 steroid users. Participants were recruited from a local safer injecting service, rather than bodybuilding gyms, in order to access a wider cross-section of steroid users. A limitation of this approach is potential sample bias towards those showing more health optimising behaviours.

Results: The research findings highlight that patterns of steroid use varied according to motivation for use, experience and knowledge gained. Most reported having had little or no knowledge on steroids prior to use, with first use being based on information gained from fellow users or suppliers - sometimes inaccurate or incomplete. In accounting for their practices, many users differentiated themselves from other groups of steroid users - for example, older users expressed concern over patterns of use of younger and (what they saw as) inexperienced steroid users. Implicit in these accounts were intimations that the 'other' group engaged in riskier behaviour than they did.

Conclusions: Examining social contexts of use and user beliefs and motivations is vital to understanding how 'risk’ behaviours are experienced so that this, in turn, informs harm reduction strategies. This paper examines the ways in which use of steroids is socially situated and the implications of this for policy and practice.

Keywords: anabolic-androgenic steroids; performance and image enhancing drugs; risk environment; harm reduction 
"It wasn't an easy decision. We were actually terrified, we were terrified even starting off on the tablets we were like, 'I don't know if we want to do this', but we did. It's one of those things I suppose once you do it, you get used to it, but yeah I was really apprehensive to be doing it to be honest. There was a lot of negative points. I was more worried about the side effects, how we'd react to it, so, but at the same time we wanted to get bigger quickly, so" (22 year-old male)

\section{Introduction}

Nationally, although difficult to measure reliably, survey data strongly suggests that the use of anabolic-androgenic steroids (hereafter referred to as steroids) is on the rise (Kimergård and McVeigh, 2014b). The Crime Survey for England and Wales estimates that in the period 2014/15 there were 293,000 16 to 59 year olds who had ever used in their lifetime ( $0.9 \%$ of the population), with 73,000 of these being use in the last 12 months $(0.2 \%)$ and 24,000 in the last month (Home Office, 2015).

The numbers using steroids and other performance and image enhancing drugs (PIEDs) are a cause of concern for those seeking to reduce health harms, especially as the use of these is no longer confined to body-building enthusiasts seeking to compete. Although the use of steroids to improve and enhance performance, appearance, and musculature is well documented historically, the broadening reasons for changing one’s body (cf Fisher, 2002; McCabe and Ricciardelli, 2003; Olivardia et al., 2004; Shilling, 2003) have extended the use of steroids far beyond its origins in professional sport and bodybuilding (Evans-Brown et al., 2012). Steroid use is now also part of a broader societal milieu (Kraska et al., 2010) where increasing numbers seek to optimise their bodies 
through an ever-widening range of licit and illicit drugs and supplements, sometimes overriding health concerns - as highlighted in the above quote.

Health risks in steroid use include serious organ damage, sudden cardiac death, reduced fertility, gynecomastia in men and masculinisation in women as well as a range of other cardiac, liver and health disorders; these, nonetheless, are not inevitable and are, for the most part, dose and administration dependent (Darke and Torok, 2014; Frati et al., 2015; Kanayama et al., 2009; Maravelias et al., 2005; van Amsterdam et al., 2010).

Concerns over numbers using and the potential for health harms have led to media hypes about steroids (Kraska et al., 2010) and to declarations that 'Public health faces a new kind of drug problem’ (Evans-Brown et al., 2012, p.9). In addressing steroid use, many countries have adopted prohibitionist fear-based approaches to policy, especially within the professional sports arena (Coomber, 2013). Some, such as Sweden, Belgium and Denmark, have adopted zero tolerance measures to steroid use and supply both inside and outside of professional sports - actions which Mulrooney and van de Ven (2015) argue are informed by wider anti-doping policies. Fear-based approaches to dealing with drug-related harms can lead to practices which end up hurting those who were initially intended to be protected by the policy (Coomber, 2013; Reinarman and Levine, 2004; Seear et al., 2015). Drug harms are shaped, and often exacerbated, by such wider macro-structural factors (Dalgarno and Shewan, 2005; Rhodes 2002, 2009; Taylor et al., 2016).

In developing drug policies on steroid use, it is important to examine how macro-structural factors impact on individual lives. The spaces and places in which individuals carry out their day-to-day lives are influenced by social and structural factors that interplay to increase or reduce risk and/or 
harm (Rhodes et al., 2005; Rhodes and Simic, 2005). In examining drug harms, Rhodes (2009, p.193) calls for a ‘social science for harm reduction' grounded in a 'risk environment' framework an approach that gives primacy to context, both at a macro and micro level, when understanding and seeking to reduce health harms.

The risk environment can be envisaged as the space in which multiple factors (physical, social, economic, policy) interact at different levels (micro, macro) to increase the potential of harm (Rhodes 2002, 2009). The risk environment approach has had notable success in increasing understanding of why certain risky behaviours persist among groups who are either knowledgeable of the risks related to their behaviours and/or who are motivated to stop those behaviours as well as those less knowledgeable and/or motivated. There is now a growing body of work unpacking the risk environments of substance use in multiple settings, including in relation to overdose (Moore, 2004; Green et al., 2009), syringe sharing (Rhodes et al., 2003; Small et al., 2006; Strathdee et al., 2010), and sex work (Shannon et al., 2008a, 2008b).

The risk environment approach offers a critique on a tendency in the behavioural sciences to emphasise risk practices, such as steroid use, as something primarily determined by individual action and resolved through individual responsibility (Rhodes, 2009). The use of substances - such as steroids - is socially situated, with multiple factors interacting and influencing each individual user. In developing interventions on steroid use, there is a need to understand this wider context as well as the motivations, experiences and patterns of use of steroid users. Examining social contexts of use and the social and cultural meanings individuals attach to their risk practices is vital to understanding how risk behaviours are experienced and displayed so that this, in turn, informs drug policy and practice. 


\section{Research methods}

This study of the motivations, practices and accounts of steroid users was part of a larger study on PIED use and supply in a mid-sized city in South West England carried out in 2013. For the wider study, the research approach adopted was that of rapid appraisal (RA). RA typically involves mixedmethod research with the aim of gathering data about a particular issue in a timely manner in order to provide evidence-based recommendations for policy and practice (Coomber, 2015; Quine and Taylor, 1998; Rhodes et al., 1999; Stimson et al., 1998). In this case, local drug and alcohol service commissioners keen to better service provision wanted to gain insights into the local PIED market as well as find out about the composition of locally sourced PIEDs and user practices and motivations. A total of thirty-two participants were interviewed, including PIED users, gym owners/managers and local suppliers. Ten samples of local 'street' PIEDs were also analysed using gas chromatographymass spectrometry (GC-MS) and reported on (see Coomber et al., 2014).

This paper focuses on qualitative semi-structured interviews carried out with twenty-two steroid users, a sub-set of the total who, as well as being questioned about the local drug market, were interviewed on their motivations for using steroids and their user practices. The aim for this set of interviews was to explore pathways into steroid use, motivations behind use and behaviours around steroid use. Topics covered were: first experiences of steroid use; types of steroids and other PIEDs used; motivations; sources of knowledge on steroids and injecting; current using and injecting practices; accessing needles; side effects; accessing steroids; and views on harm reduction strategies.

Participants were recruited at a local safer injecting service through purposive and snowball sampling (Shaghaghi et al., 2011). A poster about the research was put up in the service with a 
contact number. Service providers and the research interviewers also approached service users directly and asked if they would be willing to participate. Interviews were carried out in a private room, typically at the service, and were audio recorded. At the end of the interview, participants were asked to hand out information leaflets on the research to other steroid users in their network as part of the snowball sampling strategy. Recruitment was focused at the local safer injecting service in order to access a wider cross-section of steroid users than those attending bodybuilding gyms. A limitation of this approach is potential sample bias towards those showing more health optimising behaviours by having accessed the safer injecting service in the first place.

In recognition of participants' concern for total anonymity, audio consent was requested in place of written confirmation (Coomber, 2002). Participants also received $£ 10$ as reciprocal payment for their time. Ethical approval for the research was granted by Plymouth University’s Faculty of Health, Education and Society Research Ethics Committee.

Interviews were transcribed and the data was coded and analysed thematically, with the assistance of NVivo software (Bazeley and Jackson, 2013). The thematic analysis was inductive and iterative as emergent themes were identified and clarified (Boyatzis, 1998). Initial coding developed from the interview guide, with subsequent codes emerging throughout the coding process.

\section{Sample Characteristics}

Of the 22 respondents, most were male with only one being female. The majority described themselves as being 'White British', with only two from other ethnicities - one stated he was mixed 
race and another Asian British. Ages of respondents at the time of interview ranged from 20 to 44 years old, with the average age being 31. Just over half started their use as young adults (16 to 24 years old), with the youngest starting age being 16 and the oldest starting age being 38. Most had less than three years experience of steroid use, with the range being from two weeks to 18 years. Half of the respondents were unemployed at the time of the interview, eight were in employment and three were students.

\section{Policy and social context}

Before going on to discuss the findings, it is important to outline the policy and social context of steroid use in the United Kingdom. In the UK, prior to 1996, steroids were regulated under the Medicines Act (Cole Kleinman and Petit, 2000, cited in Keane, 2005). Keane (2005, p.190) argues that 'increasing medical, public and media concern about an epidemic of abuse' led to changes in legislation. Now regulated by the 1971 Misuse of Drugs Act, steroids have been classified as Class C drugs whereby the manufacture, supply or intent to supply steroids without a license is a crime. With a view to curbing online purchases (ACMD, 2010), it became illegal in 2012 to import steroids into the UK via freight services - such as post or courier. Possession for personal use is legal and it is still legal for users to bring in steroids purchased while abroad as long as they are for personal use only (Public Health Wales, 2014).

A harm reduction approach to steroid use is favoured in the UK (ACMD, 2010; Bates et al., 2013). Service provision ranges from needle distribution, safe disposal of used injecting equipment, health 
education and medical examinations to advice about diet and weight training in steroid clinics (Kimergård and McVeigh, 2014b).

Despite possession for personal use being legal in the UK, steroid use is an activity that is stigmatised within wider society (Monaghan, 2002). For some respondents, their steroid practices were tied to managing this stigma. Some hid their use from family, some avoided gaining too much muscle mass so that others would not question them about potential steroid use, and others denied use.

\section{Findings}

\section{Motivations for use}

Supporting the findings of previous research into steroid use (Cohen et al., 2007; Grogan et al., 2006; Kimergård, 2014; Kimergård and McVeigh, 2014a; Monaghan, 2001a, 2002; Van Hout and Kean, 2015), respondents, although coming from different backgrounds and experiences, were unified in their desire to modify their appearance and/or enhance their performance. Most were motivated to use to gain more muscle and to move beyond what they had achieved by training naturally.

Just to get bigger really. You reach a point where, after training for so long you sort of reach a point where you don't make any progress anymore. When you train naturally you reach sort of a boundary and then with steroids, it will take you past that boundary. (22 year-old male) 
In line with images of 'ideal' male bodies in the West (Kanayama et al., 2012), most described a specific type of muscular body that they desired. They wanted to "look muscular” and “toned”, with many making a point of noting that they did not want to become "massive".

I want to be like a middle-weight boxer in size, you know, not too big but not small. I just want to be toned. (29 year-old male)

I didn’t want to be huge and puffy; I just basically wanted to stay lean but a little bit more vascular. (42 year-old male)

Many spoke of the positive feelings that came with achieving these goals, speaking of the “confidence boost” it gave them. One compared his steroid use to ecstasy use, stating that he experienced the "same high sometimes" in terms of how it made him feel "really confident and good in [him]self”. Another spoke in terms of feeling addicted to being admired.

You visually look very good and any opportunity, you want to show it off and say, 'Look at me, look at my physique’, and people go, 'Whoa!' That's quite an addiction on its own and that is a problem. (42 year-old male)

For a few, these benefits were tied to their age. Five respondents were between 40 to 44 years old. Some of these highlighted how affirmative it felt to "look good" at their age:

I just get a buzz off it, a buzz off looking good. Nothing better than 40 years old and still having a nice shape. (41 year-old male)

\section{Different pathways into steroid use}


Despite the common goal of image enhancement, respondents came into steroid use from a variety of pathways. As highlighted in previous research, steroid users are not a homogenous group; they show heterogeneity in their beliefs, motivations and behaviours (Maycock and Howat, 2007; Probert et al., 2007; Van Hout and Kean, 2015). By accessing our respondents through a local safer injecting service, we were able to interview a wide range of steroid users. These could be grouped into competitive bodybuilders and powerlifters; ‘occupational users’ (Seear et al., 2015); former/current users of other illicit drugs; and those who solely wanted to improve their image.

Three of those interviewed used steroids to compete in bodybuilding competitions and two planned on taking part at a future date. One used steroids to improve performance in powerlifting competitions. For the sole female steroid user interviewed, her steroid use was associated with her desire to compete in the 'physique' category, the more muscular category in bodybuilding for women. Recognising the stigma associated with female competitive bodybuilders (Jespersen, 2012), she stated, “It doesn’t suit everyone’s tastes but that's what I like”.

Some respondents came into steroid use through their occupations - for example, the armed forces and security industry. They described steroid use as being normalised within these environments.

There is a lot of steroid use in the army. The guys are blasé about using steroids. It doesn’t mean as much as it did before. (41 year-old male)

An additional sub-group included former/current users of other illicit drugs, such as heroin, cocaine and amphetamine - an occurrence that has been noted by various studies (Cornford et al, 2014; 
Dodge and Hoagland, 2011; Hakansson et al., 2012; Petersson et al., 2010; Sagoe et al., 2015). Just under a third of respondents stated that they started using steroids in order to put on weight they had lost during their illicit drug using years. One describes how he felt he "had to in a way" start using steroids as he “wasn’t putting nothing on”. For another, his brief foray into steroid use was to prevent those around him from thinking he had relapsed to using heroin again.

I needed to get a bit of weight put on because ((laughing)) every time I went round to see my mother she would say, ‘God, haven’t you lost weight? Are you back on the stuff again?’ I’m like, 'No, I’m not on the bloody stuff!’ And it was really panicking me. People were saying, 'Oh, you're drawn in and that'. I’m like 'Crikey, I wish I could put weight on to shut everyone up.’ (33 year-old male)

\section{Patterns of use: managing risk (or not)}

There was a demonstrable lack of awareness about safe practices in steroid use and many were unperturbed over this. Nearly half reported little or no concern over side effects or other health risks - mostly accepting them as potentially part of using.

I’m just not interested in whatever, it doesn't bother me. Everything's got a consequence, hasn’t it obviously, so yeah, whatever it is, it doesn’t concern me. (28 year-old male)

Nevertheless, many did develop their own theories about what constituted safe practice and had their reasons for particular patterns of use.

Reliance on fellow users and/or supplier for information 
Most respondents reported having had little or no prior knowledge on steroids prior to using and that their approach to first use was based on knowledge gained from talking to former/current users or their supplier, referring to their experience to guide them. Consistent with Maycock and Howat's (2007) findings, trusting fellow users was a recurrent theme in the data. Maycock and Howat (2007) describe how users in their research developed networks of social trust, obligation and reciprocity where information on steroid use and purchase was shared. As one respondent in our research noted, this reliance on gaining knowledge from fellow users is a potentially risky practice:

Somebody will say to you, 'Oxy is very heavy on your liver', and you think, 'Right, okay, I'm not going to do that then'. But you're quite happy injecting something else ... It's only when somebody will actually say, 'Actually your testicles might shrink to the size of nothing', that you might sort of have some thought about it. (42 year-old male)

Included within this social network of former and current users were family members. Six had a partner or family member (father, cousins and brother-in-law) who were current or former users and who provided advice on steroid use and injecting practices. One 21 year-old describes why his initially reluctant father ended up giving him advice:

My Dad used to be a pretty big bodybuilder... He told me to stay away from it. [Did he? So, did you get advice from him, or who?] Yeah, because he said he would rather I come to him: 'If you are going to do it, you're going to do it and I would rather you come to me for advice.’ (21 year-old male)

Wenger et al. (2016) describe such a dilemma as one of 'moral ambivalence'. In their research on injectors of other illicit drugs (such as heroin and cocaine), they found that when users initiated others into injection drug use they displayed a moral ambivalence that was characterised by 
objections to facilitating initiation into injecting drug use being overridden by immediate concerns to reduce harm, such as in the case above.

These sources of knowledge were relied on by many respondents who often sought no further information. Just under a third did carry out some research on the internet but only a few had undertaken more serious research or gone to the local safer injecting service for advice prior to use. Some recognised that the nature of the information given by fellow users or dealers was often incomplete or inaccurate.

In terms of learning how to inject, most were taught by fellow users or family. Again, most never went on to seek more formal training, relying instead on what they had been taught by their friends, family, dealer, leaflets and/or the internet (including YouTube videos on how to inject). 'Stacking' and 'Cycling’ steroids

The most popular steroids first used were the steroids Deca-Durabolin and Sustanon-250. One respondent described Deca-Durabolin, most commonly referred to as Deca by users, as being known as the "safe steroid” in gyms. Half of respondents stated that they 'stacked' their first steroid, in other words they took a combination of two or more steroids. The most popular mix was Deca-Durabolin and Sustanon-250.

After initial use, in moving on to using other steroids, most sought advice from fellow users or dealers about combinations to take - supporting the findings of previous studies (Grogan et al., 2006; 
Maycock and Howat, 2007; Monaghan, 2001a). Many spoke of experimenting with different steroids, stacking combinations and dosages to see what worked best for them.

I was trying to cocktail different ones to see which one worked better for me and when I did find the one that works best for me, I’ve just been using that one ever since. (21 year-old male)

Another area of misinformation and inconsistent practice was 'cycling' of steroid use, what Bloor et al. (1998) term 'cycling theory'. Many felt that steroids are safer to use if not used continuously. The main reason given for having "off” periods was to give the "body a rest”. For those who used in cycles, they varied from being in cycles lasting from four to 12 weeks to having PCTs (post cycle therapy) lasting four to six weeks and "off" periods lasting six months or more.

The literature on the adverse health effects of steroids cites the risk of prolonged use of steroids, especially at high doses (Kanayama et al., 2008; van Amsterdam et al., 2010). Just over a third of respondents did not cycle and used steroids straight through without breaks, varying from a period of use of 5.5 months to two years. Some of these used continuously as they were unaware of the practice of cycling and/or were uninformed as to whether this was in reality a more efficacious method. One spoke of using steroids for two years straight as his dealer had not explained the practice of cycling and having rest periods, something he now regrets. Others were aware and decided to continue using in fear of losing gains made.

Managing side effects 
In line with previous research (Evans-Brown et al., 2012; Monaghan, 2001a), those that described side effects in themselves or friends spoke of acne, itchy back, boils, abscesses, hair loss, lower sex drive, irritability, changing facial features (square jaw), gynecomastia ('bitch tits'), and feeling emotional. Many felt these effects were due to inappropriate patterns of steroid use, counterfeit steroids or the characteristic effects of certain steroids.

Some also spoke of feeling “angry” and "willing to fight anyone” - a condition they referred to as 'roid rage', the popular term commonly used in the media. The existence of 'roid rage' is contested in the literature (Dunn, 2015; Lundholm et al., 2015; Oberlander and Henderson, 2012; van Amsterdam et al., 2010). While it is recognised that users may have increased feelings of aggression or irritation, the images of spontaneous drug-induced violence propagated by the media are largely myth (Llewellyn 2014). Nevertheless, these images were salient and meaningful to some respondents who spoke of trying to manage these symptoms. One had taken up boxing to give him "somewhere to focus [his] anger”. Another started using valium to keep him “chilled”:

I used to do a lot of valium when I was on steroids to keep me calm as well. It sort of works as well, it stops you having the rages. (34 year-old male)

\section{Quality control}

Supporting the findings of Maycock and Howat (2007) and Fincoeur et al. (2015), the majority of respondents reported obtaining their steroids from fellow users or gym staff. Internet sourcing was

generally not considered a viable option as the element of trust was missing unlike in personal contact. Few doubted the reliability of the steroids they accessed - trusting their source, with nearly half reporting little or no concern over side effects and other health risks. Nevertheless, some carried 
out checks to help ensure they were getting “genuine articles”. These included examining the packaging, ensuring a hologram was on the bottle, ensuring there were weakness points on the vials so that they can be easily snapped off, and ensuring that lids are sealed.

Despite few doubting the reliability of the steroids accessed, the forensic analysis of the 10 samples sourced revealed that only three actually contained what was stated on the packaging and those that did had very low active ingredients compared with the strength indicated (see Coomber et al. 2014 for further discussion on this). This is in line with international studies which highlight the variation in the forensic composition of steroids (Coopman and Cordonnier, 2012; Graham et al., 2009; Kohler et al., 2010; Pellegrini et al., 2012; Thevis et al., 2008). Coomber et al. (2014, p. 138) point out, however, that caution is needed in extrapolating health risks from such data: 'inauthentic substances will present different risks and many of these will not be necessarily high risk nor the product of cynical acts'.

Accessing and using needles

The vast majority of respondents injected their steroids rather than solely taking them orally consistent with the findings of previous research (Cohen et al., 2007; Larance et al., 2008). In light of this, users need to access needles. For many years, steroid users were hesitant about accessing these via safer injecting services, associating such services with ‘junkies’ and ‘druggies’ and in turn not seeing themselves as part of a comparable population (Simmonds and Coomber, 2009). Research

suggests that this has now shifted and that, in many parts of the UK, steroid users now outnumber other more traditional users of safer injecting services - heroin/opiate users (Chandler and McVeigh, 
2013). At the research site, the local safer injecting service in question showed a steady growth in steroid clients so that by 2014, 40\% ( $\mathrm{n}=263)$ of registered users were steroid injectors.

Not surprisingly, given respondents were recruited via the local safer injecting service, most of them stated that they got their needles from this service, with only a few also accessing needles from pharmacies, friends or their dealer. Respondents stated that they felt comfortable accessing the safer injecting service, highlighting the ease of access, privacy, anonymity, and the fact that it was a free and friendly service where they could get advice. Nevertheless, the issue of stigma still arose. Many discussed how friends or acquaintances avoided going into the local safer injecting service or pharmacies to get their needles out of a fear of being recognised. As a result, several fetched needles on behalf of others, with some receiving payment.

In terms of accessing needles via pharmacies, some did not even know that they could do this. Those who did, supporting the findings of Simmonds and Coomber (2009), spoke of feeling embarrassed at being potentially thought of as a “junkie or a druggie”.

The needle for 'growth' is the same one that the junkies use. If you go into a chemist and ask for them the women looks at you and automatically thinks 'Ahh junkie'... It's as embarrassing as hell then, isn’t it. (33 year-old male)

While respondents were not directly asked whether needle sharing took place, they were asked about what happens when people run out of needles. Most spoke of getting more needles at the local safer injecting service, at a pharmacy or from a friend. None spoke of sharing used needles. Previous research has found lower rates of the sharing of injecting equipment among steroid users and lower

incidences of blood-borne viruses when compared to other injecting drug users (see Chandler and McVeigh’s 2013 review). Nevertheless, researchers highlight the importance of examining 'risky' practices that can increase the risk of blood-borne virus transmission among steroid users (ACMD 
2010; Hope et al., 2013; McVeigh et al., 2016; Seear et al., 2015; van Beek and Chronister, 2015). A UK study, with 395 male participants, found a similar prevalence of HIV among steroid-injectors as among other injecting drug users, and highlighted factors such as sexual risk behaviours, other injecting drug use and the sharing of vials, syringes and needles (Hope et al., 2013).

\section{Accounts of use: Downplaying risk}

As well as examining patterns of use, it is important to discern how individuals talk about their use and how they position themselves in relation to their 'risk' practices. Of significance is that respondents, while acknowledging risk of harm, often downplayed their risk behaviours by using what Monaghan (2002) has termed ‘the rhetoric of legitimisation'. Respondents legitimised their practices through four main rhetorical devices, which were used interchangeably by some: describing steroid use as a normalised activity within some of their social circles; denying harm; using a rhetoric of competency; and distinguishing themselves from what they saw as other riskier users.

\section{Normalised activity}

In line with previous research (Monaghan 2001, 2002; Van Hout and Kean, 2015), many respondents, in accounting for their use, normalised it, describing moving in social circles where use

was common - either among friends, users in gyms they frequented, within competitive bodybuilding or within their occupational roles (armed forces and security industry). 
It's just because everyone else is really. I mean you don't want to be the smallest in the gym (28 year-old male)

Because my friends were doing them... Because it’s a fairly popular thing to do, I think.

Quite a lot of males have more than likely done it at some point. (23 year-old male)

\section{Denial of harm}

Consistent with Monoghan’s (2002) findings, many legitimised their own patterns of use with a rhetoric of denial of harm.

Deca is the best for me. It has few side effects. In low doses it’s beneficial to the body. My health is much better when I'm on steroids. (41 year-old male)

This belief in the safety of low doses of steroid use resonates with the findings of Grogen et al. (2006) and Kimergard and McVeigh (2014). The quote above also highlights how some felt 'healthier' on steroids. For an ex-amphetamine user, his use of steroids was a different and positive experience, one that also made him feel healthier:

This is the best drug I've ever done, ((laughs)) because it makes you feel a lot healthier and my depressions going because I'm getting a lot bigger, and I'm happy in myself. Going to the

gym five days a week, obviously makes a healthy mind doesn't it? And working out (29 yearold male) 
He also differentiated his steroid use from his other drug use - minimising harm - stating that “it’s sports enhancers really, and you don’t feel like a druggie as such”.

\section{Rhetoric of competency}

Some legitimised their patterns of use through a rhetoric of competency, a stated ‘ethnopharmacological knowledge’ (Bloor et al., 1998) of ‘safe’ steroid and other PIED use. In using this rhetoric of legitimisation, respondents downplayed their risk practices. For example, one young man described using Insulin “to keep [his muscle] gains”, a practice he recognised as risky in that "You can kill yourself within a few minutes of using it... [as] you can give yourself a diabetic coma". He nevertheless legitimised his use through a rhetoric of competency:

I've done a lot of research into it before I even touched it... I’ve researched it so much and I know what my body needs. I don’t abuse them. I know exactly what to eat, when to eat to make sure I get enough sugars in my body so I can hold enough sugars so I don’t go into a diabetic coma (21 year-old male)

Distinguishing themselves from other users

Unlike previous research (Monaghan, 2002; Simmonds and Coomber, 2009; Kimergard, 2014), the steroid users in our sample did not legitimise their practices in comparison to other illicit drug users 
(recreational or habitual), but in comparison to others within the PIED-using community. This took two main forms: first, distinguishing themselves from larger bodybuilders, what some termed “meatheads”, and second, those who saw themselves as more experienced users distinguishing themselves from inexperienced and generally younger users.

Many distanced themselves from stereotypes of users they described as “meatheads”, "massive guys”, "huge”. One assuaged his use by saying he never wanted "to do it to the extreme”. Even some of those involved in competitive bodybuilding described not wanting to be "huge and ridiculously silly”. Most stated that they took steroids to gain muscle mass, but to not look too big.

There was also a group of PIED users, those who considered themselves experienced bodybuilders, who differentiated between their own use of steroids and what they saw as the riskier practices of other inexperienced and generally younger users. Many expressed concerns over young people’s steroid use and their motives. One respondent made a distinction between what he considered to be his valid motive for using steroids to compete versus younger people’s less valid motive "to look good”.

Me taking performance enhancing drugs for a competition is for competing, and that's why I've been doing it. But they see you like that and they want to look like that... 'I want to look good'. That's not the reason to use steroids because you can still look good without the use of steroids (42 year-old male) 
Many of the older bodybuilders felt that steroids were more widely available and that young men were now using them to enhance their looks, rather than for serious bodybuilding. The concern about this increase in use among young men was focussed around their lack of knowledge on safe steroid use - such as safe injecting practices; types, dosage and mixtures of steroids to take; the need to take breaks between cycles; and to not drink alcohol while on steroids.

Yes, you get too many youngsters who just want to go and do it, having never trained before, buy whatever they can and just, they ain’t got a clue. I've seen people try and inject steroids into their veins. (41 year-old male)

Implicit in these 'othering' accounts, be it distinguishing themselves from larger bodybuilders or younger users, were intimations that their own practices were less 'risky' than those of the other group. The issue here is that the rhetoric of legitimisation used by many respondents glossed over potentially harmful practices. For some there were mismatches between their 'legitimisation' accounts and their practices. One respondent who legitimised his use by contrasting it with that of younger PIED users, went on to betray his own risky practice of continual steroid use without cycling.

I would say if I'm honest I've probably been doing it coming on and off two years, and I have to be honest with you, I’d say my cycling has pretty much stopped (42 year-old male)

\section{$\underline{\text { Ambivalence and stopping steroid use }}$}


Despite respondents accounting for their steroid use in the ways described above, for some there was an underlying ambivalence about their use. Most respondents at time of interview were current steroid users, though there was a wide variation in time of use among them, ranging from two weeks to 18 years, with most users having less than three years experience. Some of these spoke of their plans to stop and five had already recently stopped using. Reasons for stopping or planning to stop use were driven by concerns over health risks, legality and stigma. A few stopped because they did not see the desired effects.

This ambivalence about steroid use was uppermost in the minds of some of them during their interviews. One 22 year-old spoke of always having had “a negative view of steroids”. For him using steroids was a difficult decision driven by the desire to "get bigger quickly". He rationalised his use by saying that he planned to do just one cycle "just to try and build... up a bit” and that he then planned to "draw a line at it”. At the time of interview, he had completed the one cycle he intended to keep to. He had made gains but was not entirely satisfied. He had even begun looking for legal alternatives on the internet - alternatives driven by his concerns over side effects, legality and financial cost. And yet, he spoke of the double bind of not wanting to lose all the gains he had made through steroid use:

It's one of those things I don't really want to go back on to it if I'm being entirely honest and at the same time I don’t want to lose it all. I don't want to lose my size and go back to what I was, so. It's a bit, it's a bit shit.

This highlights Griffiths et al.’s (2016) recent call for health professionals and researchers to recognise the allure of steroids precisely because they are effective at building muscle mass in a short 
amount of time. They point out that this allure 'helps to explain why many steroid users are so reluctant to discontinue use and why those who do are prone to relapse and return to use' (Griffiths et al., 2016, p.375).

\section{Discussion and Conclusion}

The findings presented here help build an emic understanding of the risk environment for steroid users in one UK city, situating steroid use harm as but one concern for users alongside multiple competing priorities in their lives. A focus on risk as socially situated offers impetus to understanding how risk environments are experienced and embodied as part of everyday practices and how this might inform interventions.

At the macro level, steroid use is situated within a prohibitionist framework whereby the supply and composition of steroids is determined by an illicit market and where use is stigmatised within wider society (Coomber et al., 2014; Monoghan, 2001a). It is also situated within the contemporary structural and cultural conditions of neoliberalism and normative ideals of male bodies, consumerism and individualism. Hakim (2016) has recently argued that the rise in numbers of young British men going to the gym to fashion toned muscular bodies points to the current historical moment in Britain of continued neoliberal austerity. Young adults have been especially affected by austerity measures and job insecurity and in this climate 'many have begun to deploy a strategy of value-creation historically associated with less privileged groups - namely, bodywork’ (Hakim, 2016, p.86).

Drawing on 'tropes of the visual cultures of contemporary consumer capitalism', young men share images of themselves on social media selling 'an apparently successful version of themselves, with success being signified through the achievement of a muscular body’ (Hakim, 2016, p.90). These 
varied and multiple macro levels of environmental influence impact dynamically and reciprocally at the micro level on individual steroid users, shaping motivations, experiences and patterns of use.

At the micro level, the respondents in this study were motivated in their use of steroids to mainly enhance their image, rather than their performance. Most wanted to achieve a particular type of muscular body, one that was "toned”, but not "massive”. Nevertheless, steroid users were not a homogenous group; they were heterogeneous in their pathways into steroid use and in their practices and beliefs. Some came into steroid use via their occupations, others via use of other illicit drugs, and a few with an interest in taking part in competitive bodybuilding. While nearly half had little or no concerns over side effects or health risks, most sought information from fellow steroid users. They saw fellow users as reliable sources both for acquiring and for providing information about steroid use, highlighting how trust is a central feature in a social network defined by shared values in steroid use and image enhancement. However, this information was oftentimes incomplete or poorly researched (and sources of poor quality or inauthentic). Respondents also, while acknowledging risk of harm, often downplayed their risk behaviours through a 'rhetoric of legitimisation' (Monoghan, 2002). Many legitimated their practices by comparing themselves to other steroid users, be it larger bodybuilders or younger users, and in the process minimised the harm of their own patterns of use by intimating that the other group’s practices were riskier. There were sometimes mismatches between their 'legitimisation’ accounts and their practices - betraying potentially harmful behaviours that their accounts glossed over. Also evident in some of the interviews was a theme of ambivalence

about steroid use. Driving this ambivalence (and plans for stopping steroid use) were concerns over health risks, legality and stigma. 
In examining the social contexts of steroid use and the social and cultural meanings individuals attach to their risk practices more effective drug policies can be developed. The risk environment framework is useful for this as, contrary to contemporary public health and health promotion discourses which emphasise individual choice and informed action as primary risk management solutions (Coomber, 2012; Kemshall, 2010; Petersen and Lupton, 1996; Rhodes, 2009), it:

envisages drug harms as a product of the social situations and environments in which individuals participate. It shifts the responsibility for drug harm, and the focus of harm reducing actions, from individuals alone to include the social and political institutions which have a role in harm production (Rhodes, 2009, p.193).

Thus, on a macro level, prohibitionist drug policies need to be questioned as to their role in producing the drug harms they seek to ameliorate. Recognising the fact that steroid use does and will continue to occur, further research is needed into effective alternative drug policies, such as regulation. As argued elsewhere (Coomber et al., 2014, p.143), 'prohibition enforced differentially around the world has led to a black market in steroid where the prevalence of poor-quality and/or inauthentic... products appears to be continuing to rise.' Regulation would ensure quality control of products being bought and reduction in risk practices.

There is also a need to be cognisant of the attendant role of the cultural mechanics and impacts of neoliberalism. Smith and Raymen (2016) have recently called on researchers to recognise the normalisation of harms associated with neoliberalism, especially within commodified leisure activities such as is bodybuilding. If Hakim's (2016) previously outlined argument to explain the rise in young British men working out is accepted, then we can expect an associated rise in the number of 
young men using steroids to, in the words of one of our respondents, “quicken the process”. As Griffiths et al. (2016) state, steroids do work; they do effectively build muscle mass in a short period of time and, in this cultural and economic climate, their allure needs to be acknowledged. The challenge is addressing this.

In the meantime, harm reduction strategies need to be expanded. While recognising that harm reduction discourses can act as sites of governmentality responsibilising individuals for their behaviours (Bourgois, 2009; Moore, 2004), there have been progressive shifts within various public health interventions with some now successfully addressing the complexity of how people interact with their environment (Austin et. al., 2007; Bonell et al., 2010; Fletcher et al., 2008). Interventions for steroid users need to understand the heterogeneity of users and the specific local and wider contexts of their use. Part of this involves recognising the concern over body image; the reliance on fellow users and/or suppliers for information on how and what to use; the concurrent use of other drugs - whether these be for managing side effects or other reasons; the concern over stigma; and the use of the 'rhetoric of legitimisation' to downplay risk practices. Advances have been made in some harm reduction services which recognise a few of these issues. Some have capitalised on peer networks to provide harm reduction information via bodybuilding peer workers and some offer specific steroid clinics, with health education, medical examinations and advice about diet and weight training (Bates et al., 2013; Kimergård and McVeigh 2014b). Going forward, in addition to providing structured harm reduction programmes offering the innovative services mentioned, there should also be school/college-based, community-based and community-level interventions with appropriate peer and social network involvement that address some of the wider issues around body image, stigma and misinformation. Nevertheless, in a landscape of diminishing funding, researchers 
have raised concerns over services for steroid users and the need for more specialised interventions (Bates et al., 2013; Iversen et al., 2016; McVeigh et al., 2016).

The findings presented here highlight the importance of attaining a rich understanding of the structural, cultural and personal conditions that hinder healthier choices. Examining actual practices and contexts of use as well as how steroid use is accounted for is important in gaining an understanding of how to reduce health harms and produce 'an 'enabling environment' framework of social and structural change' (Rhodes, 2009, p. 193) that can be used to inform interventions within environments.

\section{Acknowledgments}

The research was funded by Plymouth Public Health's Drug and Alcohol Action Team. The authors would like to thank staff at the local safer injecting service for their support, the steroid users themselves who gave up their time to talk openly with us, the research assistants Sven Taylor and Karandeep Dhami who worked diligently on the research project, and the two anonymous peer reviewers for their constructive feedback.

Conflict of interest statement: No conflict of interest declared.

\section{References}


ACMD - Advisory Council on the Misuse of Drugs (2010) Consideration of the anabolic steroids. London: Advisory Council on the Misuse of Drugs.

Austin, S.B., Kim, J., Wiecha, J., Troped, P.J., Feldman, H.A. and Peterson, K.E. (2007) Schoolbased overweight preventive intervention lowers incidence of disordered weight-control behaviors in early adolescent girls. Archives of Pediatrics and Adolescent Medicine 161(9): 865 - 869.

Bates, G., Jones, L. and McVeigh, J. (2013) Update of NICE guidance PH18 on 'needle and syringe programmes’: PIEDs review. Liverpool: Liverpool John Moores University Centre for Public Health.

Bazeley, P. and Jackson, K. (2013) Qualitative data analysis with NVivo. (2 ${ }^{\text {nd }}$ ed.). London: Sage Publications.

Bloor, M., Monaghan, L., Dobash, R.P. and Dobash, R.E. (1998) The body as a chemistry experiment: Steroid use among South Wales bodybuilders. In S. Nettleton and J. Watson (Eds), The Body in Everyday Life (pp.27-44). London and New York: Routledge.

Bonell, C., Sorhaindo, A., Strange, V., Wiggins, M., Allen, E., Fletcher, A., Oakley, A., Bond, L., Flay, B., Patton, G. and Rhodes, T. (2010) A pilot whole-school intervention to improve school ethos and reduce substance use. Health Education 110(4): 252 - 272.

Boyatzis, R.E. (1998) Transforming qualitative information: Thematic analysis and code development. Thousand Oaks, CA: Sage Publications. 
Chandler, M. and McVeigh, J. (2013) Steroids and image enhancing drugs 2013 survey results. Centre for Public Health, Liverpool John Moores University.

Cohen, J., Collins, R., Darkes, J. and Gwartney, D. (2007) A league of their own: Demographics, motivations and patterns of use of 1,955 male adult non-medical anabolic steroid users in the United States. Journal of the International Society of Sports Nutrition 4(12) doi:10.1186/1550-2783-4-12

Coomber, R. (2002) Signing your life away?: Why Research Ethics Committees (REC) shouldn't always require written confirmation that participants in research have been informed of the aims of a study and their rights - the case of criminal populations. (Commentary). Sociological Research Online, 7(1).

Coomber, R. (2012) Sociology, Public Health and the Risk Environment. Paper presented at the Social Science Doctoral Training Centre Inaugural Symposium: Interdisciplinary perspectives on the ‘risk’ environment and risky behaviour, May $12^{\text {th }} 2012$.

Coomber, R. (2013) How social fear of drugs in the non-sporting world creates a framework for doping policy in the sporting world. International Journal of Sport Policy, 6(2): 171 - 193.

Coomber, R., Pavlidisb, A., Hanley Santos, G., Wilded, M., Schmidte, W., and Redshaw, C. (2014) The supply of steroids and other performance and image enhancing drugs (PIEDs) in one English city: Fakes, counterfeits, supplier trust, common beliefs and access. Performance Enhancement and Health 3: 135-144. 
Coomber, R. (2015) A tale of two cities: Understanding differences in levels of heroin/crack market related violence - a two city comparison. Criminal Justice Review, 40(1): 7 - 31.

Coopman, V. and Cordonnier, J. (2012) Counterfeit drugs and pharmaceutical preparations seized from the black market among bodybuilders. Paper presented at the Annales de Toxicologie Analytique, 2012.

Cornford, C.S., Kean, J., and Nash, A. (2014) Anabolic-androgenic steroids and heroin use: A qualitative study exploring the connection. International Journal of Drug Policy 25: 928-930.

Dalgarno, P. and Shewan, D. (2005) Reducing the risks of drug use: The case for set and setting. Addiction Research and Theory, 13 (3): 259 - 265.

Darke, S., and Torok, M. (2014) Sudden or unnatural deaths involving anabolic-androgenic steroids. Journal of Forensic Sciences, 59: 1025-1028.

Dodge, T., and Hoagland, M. F. (2011). The use of anabolic androgenic steroids and polypharmacy: A review of the literature. Drug and Alcohol Dependence, 114 (2-3): 100-109.

Dunn, M. (2015) Commentary on Lundholm et al. (2015): What came first, the steroids or the violence? Addiction 110: 109 - 110.

Evans-Brown, M., McVeigh, J., Perkins, C. and Bellis, M. A (2012) Human Enhancement Drugs: The emerging challenges to public health. Liverpool: North West Public Health Observatory. 
Fincoeur, B., van de Ven, K. and Mulrooney, K.J.D. (2015) The symbiotic evolution of anti-doping and supply chains of doping substances: How criminal networks may benefit from anti-doping policy. Trends in Organized Crime 18(3): 229 - 250.

Fisher, J. (2002) Tattooing the body, marking culture. Body and Society 8(4): 91 - 107.

Fletcher, A., Bonell, C., and Hargreaves, J. (2008) School effects on young people’s drug use: A systematic review of intervention and observational studies. Journal of Adolescent Health 42: 209 220.

Frati, P., Busardo, F., Cipolloni, L., De Dominicis, E., and Fineschi, V. (2015). Anabolic androgenic steroid (AAS) related deaths: Autoptic, histopathological and toxicological findings. Current Neuropharmacology 13(1): 146-159.

Graham, M., Ryan, P., Baker, J.S., Davies, B., Thomas, N.E., Cooper, S.M., Evans, P., Easmon, S., Walker, C.J., Cowan, D. and Kicman, A.T. (2009) Counterfeiting in performance and image enhancing drugs. Drug Testing and Analysis 1(3): 135 - 142.

Green, T.C., Grau, L.E., Blinnikova, K.N., Torban, M., Krupitsky, E., Iiyuk, R., Kozlov, A. and Heimer, R. (2009) Social and structural aspects of the overdose risk environment in St. Petersburg, Russia. International Journal of Drug Policy 20(3): 270 - 276. 
Griffiths, S., Murray, S.B., Mitchison, D. and Mond, J.M. (2016) Anabolic steroids: Lots of muscle in the short-term, potentially devastating health consequences in the long-term. Drug and Alcohol Review 35: $375-376$.

Grogan, S. Shepherd, S., Evans, R., Wright, S., and Hunter, G. (2006) Experiences of anabolic steroid use: In-depth interviews with men and women bodybuilders. Journal of Health Psychology 11: $845-856$.

Hakansson, A., Mickelsson, K., Wallin, C., and Berglund, M. (2012) Anabolic androgenic steroids in the general population: User characteristics and associations with substance use. European Addiction Research 18: 83-90.

Hakim, J. (2016) 'Fit is the new rich’: Male embodiment in the age of austerity. Soundings: A Journal of Politics and Culture 61: 84 - 94.

Home Office (2015) Drug Misuse: Findings from the 2014/15 Crime Survey for England and Wales, July. London: Home Office.

Hope, V.D., McVeigh, J., Marongiu, A., Evans-Brown, M., Smith, J., Kimergård, A., Croxford, S., Beynon, C.M., Parry, J.V., Bellis, M.A. and Ncube, F. (2013) Prevalence of, and risk factors for, HIV, hepatitis B and C infections among men who inject image and performance enhancing drugs: A cross-sectional study. BMJ Open 3: e003207. doi:10.1136/bmjopen-2013-003207 
Iversen, J., Hope, V.D. and J. McVeigh (2016) Access to needle and syringe programs by people who inject image and performance enhancing drugs. (Response). International Journal of Drug Policy 31: 199 - 200.

Jespersen, M.R. (2012) ‘Definitely not for women’: An online community’s reflections on women’s use of performance enhancing drugs in recreational sports. In: Tolleneer J, Sterckx S, Bonte P (eds.) Athletic enhancement, human nature and ethics: threats and opportunities of doping technologies. Dordrecht: Springer.

Kanayama, G., Hudson, J. I., and Pope, H. G., Jr. (2008). Long-term psychiatric and medical consequences of anabolic-androgenic steroid abuse: A looming public health concern? Drug and Alcohol Dependence 98: 1 - 12.

Kanayama, G., Brower, K. J., Wood, R. I., Hudson, J. I., and Pope, H. G., Jr. (2009). Anabolicandrogenic steroid dependence: An emerging disorder. Addiction, 104: 1966-1978.

Kanayama, G., Hudson, J.I., and Pope Jr., H.G. (2012) Culture, psychosomatics and substance abuse: The example of body image drugs. Psychotherapy and Psychosomatics 81: 73-78.

Keane, H. (2005) Diagnosing the male steroid user: drug use, body image and disordered masculinity. Health: An Interdisciplinary Journal for the Social Study of Health, Illness and Medicine 9(2): 189 - 208. 
Kemshall, H. (2010) Risk Rationalities in Contemporary Social Work Policy and Practice. British Journal of Social Work 40(4): 1247 - 1262.

Kimergård, A. (2014) A qualitative study of anabolic steroid use amongst gym users in the United Kingdom: Motives, beliefs and experiences. Journal of Substance Use 20(4): 288-294.

Kimergård, A. and McVeigh J. (2014a) Environments, risk and health harms: A qualitative investigation into the illicit use of anabolic steroids among people using harm reduction services in the UK. BMJ Open 4: e005275. doi:10.1136/bmjopen-2014-005275

Kimergård, A. and McVeigh J. (2014b) Variability and dilemmas in harm reduction for anabolic steroid users in the UK: a multi-area interview study. Harm Reduction Journal 11:19

Kohler, M., Thomas, A., Geyer, H., Petrou, M., Schaenzer, W. and Thevis, M. (2010) Confiscated black market products and nutritional supplements with non-approved ingredients analyzed in the Cologne Doping Control Laboratory 2009. Drug Testing and Analysis 2(11-12): 533 - 537.

Kraska, P.B., Bussard, C.R. and Brent, J.J. (2010) Trafficking in bodily perfection: Examining the late-modern steroid marketplace and its criminilization. Justice Quarterly 27(2): 159 - 185.

Larance, B., Degenhardt, L., Copeland, J. and Dillon P. (2008) Injecting risk behaviour and related harm among men who use performance- and image-enhancing drugs. Drug and Alcohol Review 27(6): 679-686. 
Llewellyn, W. (2014) Anabolic steroids. Paper presented at the Public Health and Enhancement Drugs Conference at Liverpool John Moores University Centre for Public Health, April $9^{\text {th }} 2014$. Retrieved August 4th 2016 from https://www.youtube.com/watch?v=UdBopxfDpRc

Lundholm L., Frisell T., Lichtenstein P. and Langstrom N. (2015) Anabolic androgenic steroids and violent offending: confounding by polysubstance abuse among 10365 general population men. Addiction 110: 100 - 108.

Maravelias, C., Dona, A., Stefanidou, M., and Spiliopoulou, C. (2005). Adverse effects of anabolic steroids in athletes: A constant threat. Toxicology Letters, 158(3): 167-175.

Maycock, B.R. and Howat, P. (2007) Social capital: Implications from an investigation of illegal anabolic steroid networks. Health Education Research 22(6): 854 - 863.

McCabe, M. P. and Ricciardelli, L.A (2004) Body image dissatisfaction among males across the lifespan- A review of past literature. Journal of Psychosomatic Research 56: 675-685

McVeigh, J., Kimergård, A., Bates, G., Hope, V.D. and Ncube, F. (2016) Harm reduction interventions should encompass people who inject image and performance enhancing drugs. (Letter). BMJ 353:i1889 doi: 10.1136/bmj.i1889

Monaghan, L. F. (2001a) Bodybuilding, drugs and risk. London: Routledge. 
Monaghan, L. F. (2001b) Looking good, feeling good: The embodied pleasures of vibrant physicality. Sociology of Health and Illness 23(3): 330 - 356.

Monaghan, L. F. (2002) Vocabularies of motive for illicit steroid use among bodybuilders. Social Science and Medicine 55: 695 - 708.

Moore, D. (2004) Governing street-based injecting drug users: A critique of heroin overdose prevention in Australia. Social Science and Medicine 59(7): 1547 - 1557.

Mulrooney, K.J.D. and van de Ven, K. (2015) 'Muscle Profiling': Anti-doping policy and deviant leisure. Deviant Leisure Research Group. Retrieved February 12th 2016 from https://deviantleisure.wordpress.com/2015/01/21/muscle-profiling-anti-doping-policy-and-deviantleisure/

Oberlander, J.G. and Henderson, L.P. (2012) The Sturm und Drang of anabolic steroid use: Angst, anxiety and aggression. Trends in Neurosciences 35(6): 382 - 292. doi:10.1016/j.tins.2012.03.001

Olivardia, R., Pope Jr, H. G., Borowiecki III, J. J. and Cohane, G.H. (2004) Biceps and body image: The relationship between muscularity and self-esteem, depression, and eating disorder symptoms. Psychology of Men and Masculinity, 5(2):112-120

Pellegrini, M., Rotolo, M.C., Di Giovannadrea, R., Pacifici, R. and Pichini, S. (2012) A simple toxicological analysis of anabolic steroid preparations from the black market. Paper presented at the Annales de Toxicologie Analytique, 2012. 
Petersen, A. and Lupton, D. (1996) The new public health: Health and self in the age of risk. (1st ed.). London: Sage Publications.

Petersson, A., Bengtsson, J., Voltaire-Carlsson, A., and Thiblin, I. (2010) Substance abusers’ motives for using anabolic androgenic steroids. Drug and Alcohol Dependence 111: 170-172.

Probert, A., Leberman, S., and Palmer, F. (2007). New Zealand bodybuilder identities: Beyond homogeneity. International Review for the Sociology of Sport. 42(1): 5 - 26.

Public Health Wales (2014) UK steroid law. Retrieved March 15th 2016 from http://www.siedsinfo.co.uk/steroid_law.html

Quine, S. and Taylor, R. (1998) Methodological strategies. In C. Kerr, R. Taylor, and G. Heard (Eds). Handbook of Public Health Methods (pp. 17-23). Sydney, Australia: McGraw-Hill.

Reinarman, C. and Levine, H.G. (2004). Crack in the rearview mirror: Deconstructing drug war mythology. Social Justice 31 (1-2): 182-199.

Rhodes, T., Stimson, G. V., Fitch, C., Ball, A. and Renton, A. (1999) Rapid assessment, injecting drug use, and public health. The Lancet, 354: 65-68.

Rhodes, T. (2002) The 'risk environment': A framework for understanding and reducing drug-related harm. International Journal of Drug Policy 13: 85 - 94. 
Rhodes, T. (2009) Risk environments and drug harms: A social science for harm reduction approach. International Journal of Drug Policy 20: 193 - 201.

Rhodes, T., Mikhailova, L., Sarang, A., Lowndes, C.M., Rylkov, A., Khutorskoy, M. and Renton, A. (2003) Situational factors influencing drug injecting, risk reduction and syringe exchange in Togliatti City, Russian Federation: A qualitative study of micro risk environment. Social Science and Medicine 57(1): 39 - 54.

Rhodes, T. and Simic, M. (2005) Transition and the HIV risk environment. BMJ 331: 220 - 223.

Rhodes, T., Singer, M., Bourgois, P., Friedman, S. and Strathdee, S. (2005) The social structural production of HIV risk among injecting drug users. Social Science and Medicine 61: 1026 - 1044.

Sagoe, D., McVeigh, J., Bjørnebekk, A., Essilfie, M., Andreassen, C.S., and Pallesen, S. (2015) Polypharmacy among anabolic-androgenic steroid users: A descriptive metasynthesis. Substance Abuse Treatment, Prevention and Policy 10:12 doi: 10.1186/s13011-015-0006-5

Seear, K., Fraser, S., Moore, D. and Murphy, D. (2015) Understanding and responding to anabolic steroid injecting and hepatitis C risk in Australia: A research agenda (Commentary). Drugs: Education, Prevention and Policy 22(5): 449 - 455.

Shaghaghi, A., Bhopal, R.S. and Sheikh, A. (2011) Approaches to recruiting 'hard-to-reach' populations into research: A review of the literature. Health Promotion Perspectives 1(2): 86 - 94. 
Shannon, K., Kerr, T., Allinott, S., Chettiar, J., Shoveller, J. and Tyndall, M.W. (2008a) Social and structural violence and power relations in mitigating HIV risk of drug-using women in survival sex work. Social Science and Medicine 66(4): 911 - 921.

Shannon, K., Rusch, M., Shoveller, J., Alexson, D., Gibson, K. and Tyndall, M.W. (2008b) Mapping violence and policing as an environmental-structural barrier to health service and syringe availability among substance-using women in street-level sex work. International Journal of Drug Policy 19(2): $140-147$.

Shilling, C. (2003) The Body and Social Theory. London: Sage Publications.

Simmonds, L. and Coomber, R. (2009) Injecting drug users: A stigmatised and stigmatising population. International Journal of Drug Policy 20: 121-130.

Small, W., Kerr, T., Charette, J., Schechter, M. T. and Spittal, P.M. (2006) Impacts of intensified police activity on injection drug users: Evidence from an ethnographic investigation. International Journal of Drug Policy 17(2): 85 - 95.

Smith, O. and Raymen, T. (2016) Deviant leisure: A criminological perspective. Theoretical Criminology. Published online before print August 11, 2016, doi:10.1177/1362480616660188

Stimson, G. V., Fitch, C. and Rhodes, T. (1998) The Rapid Assessment and Response guide on injecting drug use. Geneva: World Health Organization: Substance Abuse Department. 
Strathdee, S.A., Hallett, T.B., Bobrova, N., Rhodes, T., Booth, R., Abdool, R. and Hankins, C.A. (2010) HIV and risk environment for injecting drug users: The past, present, and future. The Lancet 376(9737): 268 - 284.

Taylor, S., Buchanan, J. and Ayres, T. (2016) Prohibition, privilege and the drug apartheid: The failure of drug policy reform to address the underlying fallacies of drug prohibition. Criminology and Criminal Justice 16(4): 452 - 469.

Thevis, M., Schrader, Y., Thomas, A., Sigmund, G., Geyer, H. and Schänzer, W. (2008) Analysis of confiscated black market drugs using chromatographic and mass spectrometric approaches. Journal of Analytical Toxicology 32(3): $232-240$.

van Amsterdam, J., Opperhuizen, A. and Hartgens, F. (2010) Adverse health effects of anabolicandrogenic steroids. Regulatory Toxicology and Pharmacology 57: 117 - 123.

van Beek, I. and Chronister, K.J. (2015) Performance and image enhancing drug injectors’ access to needle syringe programs: Responding to a public policy dilemma. International Journal of Drug Policy 26: $868-874$.

Van Hout, M.C. and Kean, J. (2015) An exploratory study of image and performance enhancement drug use in a male British South Asian community. International Journal of Drug Policy 26: 860867. 